\title{
The Steampunk Doctor: Practicing Medicine in a Mechanical Age
}

\author{
Cécile Cristofari ${ }^{1,2}$, Matthieu J. Guitton ${ }^{1,2}$ \\ ${ }^{1}$ Faculty of Medicine, Laval University, Quebec City, Canada \\ ${ }^{2}$ Institut Universitaire en Santé Mentale de Québec, Quebec City, Canada \\ Email: cecile.cristofari@gmail.com
}

Received 24 March 2014; revised 21 April 2014; accepted 12 May 2014

Copyright (C) 2014 by authors and Scientific Research Publishing Inc.

This work is licensed under the Creative Commons Attribution International License (CC BY). http://creativecommons.org/licenses/by/4.0/

(c) (i) Open Access

\begin{abstract}
Influenced by both $19^{\text {th }}$-century literature and popular representations of science, the figure of the medical doctor in steampunk fiction is marked by ambiguity. At the same time a scientist, a wizard and a mechanic, the steampunk doctor exists halfway between respectability and illegitimacy, a manipulator of bodies, a wielder of mysterious powers, a respectable and ominous character at the same time. Their role includes but is not limited to healing bodies. Indeed, steampunk examines the consequences extraordinary medical discoveries can have on both individuals and societies. It questions the meaning of "improvement" in the context of medicine, and whether it is ethical for medical practitioners to bring human bodies beyond their normal state, to the point that normality itself has to be re-defined. This paper describes the figure of the steampunk doctor and details the place and power of medicine in steampunk worlds. On the one hand, the steampunk doctor can modify bodies at will, bringing bio-engineering on a par with regular engineering, and leading to questions about the boundaries (ontological and ethical) between humans and objects, living and inanimate matter. On the other hand, their work on individual bodies can lead to transformations of their society as a whole, by modifying entire groups to suit social or political agendas, or in a quest for personal power. In the end, the figure of the steampunk doctor brings to the forefront some ethical questionings about medicine, healing, bio-engineering and human enhancement that are very relevant to the present times, in spite of the deceptively retrospective aesthetics.
\end{abstract}

\section{Keywords}

Bioethics, Doctor Archetype, Human Enhancement, Social Engineering, Victorian Medicine

\section{Introduction}

The Victorian era has inspired a wealth of literary genres, from gothic horror to early detective stories. Contem- 
porary writers are still drawing inspiration from that period (Heilmann \& Llewellyn, 2010). Among the many fictions inspired by the Victorian period in the late $20^{\text {th }}$ and early $21^{\text {st }}$ century, steampunk hold a special place. Steampunk works stage a re-imagining of the Victorian age, strongly influenced by science fiction and fantasy, where technical feats and outright miracles coexist with a setting inspired from the $19^{\text {th }}$ century. Since the appearance of the first steampunk works in the 1970's and 1980's, its popularity has grown steadily (Nevins, 2011).

As a genre, steampunk is essentially transfictional: in addition to frequently showcasing historical characters, many works give a new life to famous fictional figures from $19^{\text {th }}$-century literature, each time reasserting the ties between the literature of the Victorian era and contemporary steampunk (Saint-Gelais, 2011). Steampunk can thus be considered as a contemporary re-enactment of a fantasised $19^{\text {th }}$ century, and has formed a new repertoire of tropes that directly draw from $19^{\text {th }}$ century popular culture, re-examined through a $20^{\text {th }}$ - and $21^{\text {st }}$-century lens. Therefore, steampunk is grounded in contemporary imaginings of past tropes and technologies (Perschon, 2010). Inspired by proto-science fiction authors such as Jules Verne or H. G. Wells, pulp magazines, Victorian imagery as well as science fiction and fantasy in general, steampunk has nonetheless, in its thirty years of existence, built its own specific figures. Among them, the steampunk doctor holds an intriguing place.

In popular imagery, the doctor-or healer-is a benevolent figure of both knowledge and power (Freidson, 1970; Foucault, 1973; Hogle, 2002). In steampunk fiction, the doctor becomes a more shadowy figure, in which both characteristics are taken to the extreme and supersede the exercise of medicine itself in importance. In the particular context of the Victorian era, the doctor is, first and foremost, an embodiment of dizzying scientific progress. The steampunk doctor has ties to the figure of the isolated genius scientist, while retaining the mysterious and disquieting quality of the mediaeval plague doctor. They are often pioneers in medicine, having created their own groundbreaking medical techniques. However, the power thus acquired lends them a large measure of ethical ambiguity: the steampunk doctor can affect the human body in almost unlimited ways, hybridising it with machines or animals and turning death and illness into secondary concerns, at the potential cost of a number of moral violations.

While this initial description could fit a number of $19^{\text {th }}$-century characters (Dr. Frankenstein, Dr. Jekyll and Dr. Moreau are the first that come to mind), the steampunk doctor is fundamentally different. Frankenstein or the Modern Prometheus (Shelley, 1818), The Strange Case of Dr. Jekyll and Mr. Hyde (Stevenson, 1886) and The Island of Dr. Moreau (Wells, 1896) were all, on a certain level, cautionary tales. Their heroes bring about their own doom through their experiments, and the moral violations committed in the name of science (attempting to substitute oneself to God, creating monsters, inflicting terrible pain on innocent beings...) eventually trigger their demise. But more importantly, their science dies with them: Frankenstein gives up his attempts to create a human being and embarks upon a solitary quest to find his creature before dying in a remote place; the ingredients of Jekyll's salts run out, ensuring that with his suicide, the chemicals that enabled him to turn into Hyde will be impossible to find again; Moreau's island remains isolated and its denizens revert to bestiality, thus cancelling the effects of the original experiments. The hubris of those characters only results in the destruction of their own lives and works, without leaving a lasting trace on society.

The opposite happens with the steampunk doctor. Steampunk cannot, indeed, be solely described as a resurrection of $19^{\text {th }}$-century science fiction. It is instead a complete re-imagining of what society could have been if the evolution of technology had been radically different from the beginning, and it usually includes a more than liberal sprinkling of magical possibilities, often presented as fantastical science (for instance modern versions of alchemy, which is prominently featured in works such as Hiromu Arakawa's Full Metal Alchemist from 20012010 or Ekaterina Sedia's The Alchemy of Stone from 2008). In steampunk, the limits of science are more flexible than in traditional science fiction. Additionally, authors rarely adopt the condemning stance $19^{\text {th }}$-century literature has used us to. As a result, steampunk doctors push back the boundaries of science, with varying consequences, often positive.

The steampunk doctor thus appears as a shadowy figure, whose allegiance lie primarily with their science, rather than society. They can perform miracles on individuals, to such a degree that the ethical character of their actions can often be questioned; but their influence is at their most dramatic when they become capable of medical feats powerful enough to transform an entire society. This paper will therefore start with a discussion of the figure of the steampunk doctor and its many areas of ambiguity. From there, we will examine what power the steampunk doctor has over individual bodies, how their role encompasses but goes far beyond healing, and the ethical issues related to steampunk medicine. Finally, we will focus on the crucial issue of how the steampunk doctor's actions can affect an entire society, by acting on both individual and groups, and how this trope is, 
in fine, related to contemporary concerns about ethics and the power of medicine.

\section{An Ambiguous Figure}

While retaining their ties with medicine, the steampunk doctor is rarely a conventional medical practitioner. Instead, the very construction of their character marks their threshold-crossing nature: as they routinely straddle the boundaries between science and miracles, the ethical and the monstrous, they appear as liminal beings themselves. At their most conventional, they have an ambiguous place in society, in which they are seldom completely integrated (like Dr. X in Neal Stephenson's The Diamond Age (1995), who holds a high rank in one of the two societies he inhabits and is considered an outlaw in the other). However, they can also be portrayed as outright social outsiders (like Krank from Marc Caro and Jean-Pierre Jeunet's The City of Lost Children (1995), who lives on a remote artificial island). Their separation from the rest of society is sometimes implied by physical clues: they have made themselves physically different, thus enhancing their particular place. A good example of this duality of the steampunk doctor can be found with Dr. Jack Seward from Kim Newman's Anno Dracula (1992). While practicing in a Whitechapel medical clinic by day, Dr. Seward, who survived the ascent of Dracula, now effectively ruling London, carried on his crusades against the vampires by night, by murdering vampire prostitutes in Whitechapel. In a transformation reminiscent of Dr. Jekyll and Mr. Hyde, Newman has pinned the most antithetical identity one could imagine to the figure of the doctor, in the persona of Jack the Ripper. Unlike Jekyll and Hyde, however, Dr. Seward does not switch back and forth between two separate identities, suggesting instead that a doctor's identity can hide an important dark side. This blurring of the lines between official respectability and a darker, secret identity exemplifies the inherent ambiguity of the steampunk doctor.

This ambiguity is sometimes apparent in the title the character bears: not all doctors are called doctors. Even though their profession is known, the fact that their title does not reflect it introduces an additional measure of uncertainty. The exceptionally skilled surgeon from George Mann's The Affinity Bridge (2008) is for instance known to his patients as the Fixer. Similarly, the Blacksmith from The Iron Duke by Meljean Brook (2010) is, like the Fixer, famous for the miracles he can perform on the human body. The discrepancy between their title and their profession only indicates a far-reaching constitutive ambiguity. Both characters are ominous figures, whose services come with a price: a literal, extremely high monetary price for the Blacksmith; secrecy and service to the British crown for the Fixer, who only operates on a select few. Both are somewhat legendary characters in the world of the novel. Interestingly, both also have names that apparently undermine their quality as doctors: instead of having a title that reflects the traditional dignity of the medical practitioner, their titles indicate humbler professions, dedicated to operating on things rather than humans. Those characters combine the trite, through their title, with the uncannily advanced, through their scientific prowess; the benevolent and the threatening (as the text makes it clear that their services are not to be taken for granted). However, their darker side cannot be dissociated from their usefulness to society.

Pushing the ambiguity further, another character, Boss, from Genevieve Valentine’s Mechanique (2011), is not presented as a doctor at all but as the manager of a circus troupe. Like the Fixer or the Blacksmith, she can perform miracles on the human body, and is said to be able to save people from certain death through her surgical feats. Unlike the Fixer and the Blacksmith, however, she is not recognised by the central powers, and she is considered little better than an outlaw. Her character is a good example of the many contradictions the steampunk doctor can encompass: she appears as a motherly figure and an unyielding master both, an outlaw whose work is nonetheless coveted by the authorities, a scientist and a performer, a character who enslaves others and liberates them at the same time, by attuning their bodies to their inner nature; her scientific work also appears to involve a certain degree of magic.

The grey area does not only cover medicine and adjacent domains, but everything pertaining to the doctor, from their personal life and personality to the various aspects and uses of their profession; they even transcend the boundaries between science and magic, when the world allows it. Furthermore, their humanity itself is sometimes questioned. Steampunk portrays feats of science, and the characters who perform them are often the first to be definitively affected. The doctor's humanity is not to be taken for granted, as very often, the doctor bears a mark that sets them aside from humanity. For instance, The Strange Affair of Spring-Heeled Jack by Mark Hodder (2010) stages a secret organisation of scientists, all except one having undergone drastic modifications: Darwin and Galton had their brains fused together and their bodies replaced by automated parts; Isambard Kingdom Brunel lives on in the body of a gigantic automaton, whose last ties to humanity lie in his love for 
Florence Nightingale. In a more subtle vein, Dr. Helen Magnus from the TV series Sanctuary (Wood, 2008-2011) has become practically immortal after experimenting on herself, which allows her to operate her clinic and shelter for monstrous creatures for over a century, but also sets her apart from mankind. The architecture of her Sanctuary, a huge neo-gothic building in the middle of a modern North American city, physically marks her separation from the rest of the world. Indeed, while the steampunk doctor crosses scientific boundaries, they often precede this crossing by setting themselves apart from mankind through morphological transformations: in other words, they set themselves apart by making themselves a more integral part of their science and experimentation, even before they start using their knowledge and skills on others.

\section{An Architect of the Body}

Classically, the first function of the doctor is to heal. Healing, however, can assume very varied definitions, depending on the technical possibilities available. The $19^{\text {th }}$ century witnessed a considerable growth of scientific knowledge, supporting an exponential growth of medical techniques and success rates. Public health took a leap forward due to rationalisation of medical approaches. Enthusiasm for medical applications of emerging technologies reached a peak in the society, as regular engineers went to tremendous lengths to devise applications (sometimes unlikely) for various physical phenomena-electricity, light, rays... (Wolf, 2005). The $19^{\text {th }}$ century retains the image of a time where science progressed at an incredibly fast pace, and was mainly oriented towards the immediate betterment of society; furthermore, the somewhat inaccurate notion that $19^{\text {th }}$-century science was led by exceptional individuals working in isolation, rather than by groups or networks of scientists, is still quite pregnant in popular imagery.

Steampunk science and techniques have an unwieldy appearance, but their potency often contradicts their cumbersome aspect. In fact, there is very little that steampunk science cannot accomplish. This inevitably stretches the limits of what medicine's healing role can be. What if healing could extend to making better (Kamm, 2005; Schwartz, 2005; Bostrom, 2008)? Indeed, steampunk doctors dispose of a vast array of technical means to improve on human bodies, mechanical and biological, and can not only restore them, but definitively alter them through the addition of body parts. At first glance, steampunk appears more preoccupied with assembling mechanics than with healing bodies. Technology and medicine, however, can be enmeshed in a way that is more complex than the devising of new medical tools.

In a fictional era dominated by mechanical ingenuity, hybridisation is a crucial part of the steampunk doctor's function. It can take many forms: humans can receive mechanical parts-an extremely common case, ranging from a single mechanical piece added to a human body to the transfer of the mind into a machine. However, the hybridisation process can go considerably further, as human can be merged with animal—like the fish-like prostitutes from K. W. Jeter's Infernal Devices (1987) - in a crafting process resulting in artificial human-animal hybrids similar to those endogenously found in numerous science fiction settings (Guitton, 2013). Finally, even human-human constructs can appear, such as Darwin and Galton in The Strange Affair of Spring-Heeled Jack. The main implication is that bodies are not the same before and after passing through the doctor's clinic. The work of the doctor is not solely restorative, but can become transformative: while, in the real world, a surgeon tries to heal bodies as seamlessly as possible, ideally erasing all traces of the illness or wounds they suffered, the steampunk doctor usually leaves indelible and very visible marks. Patients are not healed, but improved through procedures that blur the limit between human and machine (Forlini, 2010).

As steampunk has been characterised by its relationship to technology, it's not surprising that an important part of the steampunk doctor's work should consist in using mechanical devices to heal their patients, or in many occasions, to improve on their bodies. Names such as "Fixer" or "Blacksmith" reflect an actual characteristic of those doctors: they literally tinker with human bodies, enhancing them with mechanical parts. Among the examples we cited, the Blacksmith from The Iron Duke is the most obvious. His very name indicates that he works with metal parts rather than humans. Indeed, his patients come to him to be definitively bound to mechanical parts. In some cases, they merely try to recover a lost biological function: the heroin, Mina Wentworth, has a mechanical heart grafted in her chest at the end of the novel, while her mother has received artificial eyes after losing hers. In both cases, the mechanical organ is superior to the biological one. Lady Wentworth's eyes are also visibly different.

Steampunk biotechnology is not different from steampunk technology in general: instead of being streamlined and unobtrusive, it is characterised by its salience and visibility (Onion, 2008). The doctor's patients are par- 
tially dragged into the grey area the doctor inhabits: they are marked, and while they can usually return to a normal life, the changes brought about cannot be undone or hidden. In a similar vein, the cast of Sanctuary includes an avatar of Dr. Watson, as a member of the group of scientists originally injected with vampire blood alongside with Dr. Helen Magnus. As a result of the injection, Watson gained a supra-natural intellect, which enabled him, among other things, to become a groundbreaking inventor. When introduced during the first season, Watson appears not to have aged in over a century, thanks to a machine of his own device that he has connected to himself. His dependency on the machine soon becomes tragically apparent, however, as the ending of the season shows it malfunction, resulting in his near-instantaneous aging and death. Watson is able of nearly-unimpaired functioning while the machine keeps him alive, but cannot survive if he is disconnected from it. This begs the question: if a machine is the only thing supporting a human life after its body has failed it, is it still the human that is alive, or is a human body supporting a living machine?

The position of the steampunk doctor as a crafter of living flesh may however seem fundamentally paradoxical. Indeed, steampunk as a genre appears primarily concerned with technology rather than biology. Can a doctor whose prime concern remains the workings of the human body truly be an essentially steampunk figure? At first glance, the doctor - unless part technician or mechanic as we outlined earlier — has little to do with the aesthetics of steampunk. A closer look, however, reveals a different reality. Biological matter can also be considered as a material, rather than an untouchable being - a view bearing considerable implications in the context of early $21^{\text {st }}$-century scientific advances. Thus, the steampunk doctor fulfils the role of the missing link between biology and technology, and also between medicine and the engineering disciplines more favoured by steampunk. Indeed, the steampunk doctor is not merely a healer: they craft living bodies like inanimate objects, they experiment with bodies as one could experiment with any material, they build and improve on them, treating biological material as they could any other.

Biological engineering has a special place in steampunk. It is hard not to associate that preoccupation of the genre with contemporary issues of bioethics: the ethical limits of medicine, surgery and genetic manipulations have been a controversial subject for decades (Francis, 2001; Robert \& Baylis, 2003; Kamm, 2005). It is therefore not surprising to find them reflected in steampunk, which voices contemporary concerns through the use of $19^{\text {th }}$-century figures. Attempts from doctors to craft living bodies for various purposes range from facetious examples (such as Paul DiFilippo's Victoria (1995), where a doctor manages to make a human-newt hybrid so convincing that it replaces the missing Queen Victoria on the throne) to more serious narratives (in Sanctuary, the injection of vampire blood turns a previously harmless man into Jack the Ripper). In all cases, experimenting with living matter is portrayed as a process very similar to tinkering: it uses trial and error to obtain creations that often remain one-of-a-kind. The seminal works of Charles Darwin and Gregor Mendel, as well as the first schools of thought based on the notions of evolution and genetics (Francis Galton's eugenics, in particular, as well as Herbert Spencer's social Darwinism) are often featured in the context of biological engineering. Many steampunk authors naturally posit that the brand new horizons Darwin opened for Western thought would have influenced the science of the time if it had been advanced enough. In fact, Charles Darwin is thus a prominent figure in the background of many steampunk works that explore some of the more ethically ambiguous possibilities of biological engineering, or even link biological engineering to mechanics to the point that they become indistinguishable—as happens in Scott Westerfeld's Leviathan (2009), where entire ecosystems are engineered as biological machines.

Steampunk thus has its own answer to the question of cybernetics: not only man and machine can be merged, but biological parts and mechanical parts can be used interchangeably. A perfect example of this is given by the protagonist of China Miéville's Perdido Street Station (2003): when tasked with making a pair of wings for a crippled bird-man, he sets out without knowing whether the wings will be mechanical or biological, nor which species he will model them on. For the steampunk doctor, organs are not part of a system, but independent items. One can hope to grasp the essence of what makes a specific body part by studying enough unrelated specimens, and then construct one for any purpose, using organic or mechanical materials. The doctor is the one who can determine how to craft a body in the most efficient way. However, once the boundary between biology and technology has been bridged, the physical limits of the body itself can be transcended. Mark Hodder's works exemplify how far the merging of human and machine can be taken. Rather than thinking in terms of objects and humans, machines and animals, the steampunk scientists of The Strange Affair of Spring-Heeled Jack view all matter as fair game for experimentation and improvement, beginning with themselves. Besides Darwin, Galton and Brunel's transformations, their ally the explorer John Speke has been grafted with a mechanical brain, and 
writer Laurence Oliphant had his body fused with the genes of a white panther. The scene that shows the heroes discovering their headquarters is a statement of the ultimate identity of mechanical and biological engineering, and of the transformative power of skilled doctors.

Disposing of the technology to fix bodies and improve on them at will raises a critical question: are there any limits to what you can fix? In fact, steampunk settings often posit very few limits to the technology they enable. Machines may be cumbersome, noisy and costly to maintain, they are rarely talked about in terms of limitations. Apparent gears, metal pipes or steam exhausts do not prevent scientists from performing feats that would be difficult to imagine even with contemporary nanotechnologies. There are very few technical limits to what steampunk doctors can accomplish; the ethical limits, however, are the subject of frequent interrogations. How far is it acceptable to manipulate human bodies, and at what point do those manipulations amount to negating the humanity of the subject, instead of enhancing it? In Hodder's series, the scientists are secretly conducting their experiments on non-consenting humans, with the aim of creating races of physiologically specialised workers. Here, the transgression of scientific boundaries is immediately and obviously accompanied by an ethical transgression. If humans and objects can be merged, there remains little incentive to treat humans with more consideration than objects have always been treated.

The question of ethical limits of the steampunk doctor's activities is not only asked in the context of obvious, unambiguously condemnable violations of human dignity. The act of modification itself, even when it seems benevolent, might be inherently questionable. While steampunk rarely gives unequivocal answers to that question, some works do explore the inherent problems that come with unlimited power to improve on human beings. In the aforementioned Perdido Street Station, creating wings for a crippled creature may be construed as a benevolent act; however, the ethical problems never fall into the background. The request Grimnebulin (the steampunk doctor of the novel) makes for winged creatures triggers a catastrophe, by releasing a monster on the city. While his initial intentions were mostly honourable, they ask a question: what sacrifices, for the self or for others, can be deemed acceptable when it comes to healing someone? Furthermore, the ethical focus shifts when discovering that Grimnebulin's patient had lost his wings as a punishment for raping a woman of his tribe. We are then confronted with the following interrogation: what if a "noble" decision to restore someone's body could be unethical in the first place? Although such a questioning does not amount to making an ethical statement about medical practices in the real world (it would be wrong to assume, for instance, that Miéville's novel is telling us that criminals do not deserve to be healed), it calls into question the notion that doctors, in their roles as healers, should receive carte blanche when it comes to performing their duties. Unlimited power over the human body makes it impossible to assume benevolence as a default: as doctors hold the power to perform unethical acts as well as benevolent ones, they can never be considered above and beyond ethical questioning.

The transgressions allowed by the advances of steampunk medicine take the role of the healer far past its traditional boundaries. Steampunk healers do not fight Death; they have the power to beat it. George Mann's The Affinity Bridge and its sequels posit that the Victorian age has endured past 1901: the queen is kept alive by a complex machinery without which she could not survive. While her body decays, her intellectual functions are not altered, and she carries on with her reign. The ethical interrogations about such drastic treatment of illness and death are made explicit through the reflexions of Dr. Fabian, the creator of the machine, who secretly included a switch that might shut it down and kill the queen if necessary, though the responsibility of wondering why killing her might become necessary is left to the reader. Ironically, the third volume reveals that Victoria was actually aware of the presence of that switch. That revelation is reminiscent of a popular theme in science fiction, the artificial intelligence taking its independence and antagonising its creators; except that here, the intelligent machine in question is none other than the queen of England, and it is unclear whether she should still be considered as human even past the "natural" time of her death, or if the very idea of "natural" still means anything once life and death can be technologically controlled.

However, the most drastic impact of the steampunk doctor's work is not seen on an individual level. When physical harm, natural physiology and even death are abolished, transformations in society at large will inevitably follow.

\section{The Power to Shape Societies}

While the question of the legitimacy of using extremely advanced medical techniques on individuals is prominent, the preoccupations of steampunk writers are in fact often centred on a larger problem: what consequences 
such advances are likely to have, not only for individuals, but for society as a whole. The $19^{\text {th }}$ century was shaped by the progress of the industrial revolution. Science and technology were advancing faster than ever in history. That those changes should be as frightening as they were exciting, at a time when there was little way to know where they would stop, and if their effects would be beneficial or not, is quite understandable. In the 1980 's, science and technology had not halted by any means; however, it was becoming obvious that the dramatic transformations foreseen by science fiction writers along the course of the $20^{\text {th }}$ century were not going to happen in the immediate future. Frantic scientific progress had therefore become a phenomenon that could be examined in hindsight, rather than anticipated (James, 1994; Colson \& Ruaud, 2006). What had become clear was that progress eventually happened, and was not, in fact, prevented through the premature destruction of its agents. While this did not, by any means, remove the ethical concerns about the use of science and technology, it also meant that those concerns had to take into account actual repercussions of progress on individuals and societies, instead of being viewed through a purely theoretical, philosophical lens. Steampunk writers from the 1980's onward possess sufficient hindsight to know that progress is not an isolated, self-destructing phenomenon, but that indeed, it can successfully transform society, for better of for worse.

This is the key difference between the Victorian science fiction doctor and the steampunk doctor: the later has a tangible, sometimes dramatic impact on society. Had Moreau been the product of the imagination of a $21^{\text {st }}$ century steampunk writer, he might have been commissioned by Queen Victoria to create a race of hybrids optimised for the service of the British Empire. If Stevenson had lived in our day and age, Jekyll's formula might have been bought by a powerful government to create elite soldiers; a new avatar of Jekyll himself is enrolled for that precise purpose in Stephen Norrington's The League of Extraordinary Gentlemen (2003). Had Mary Shelley written her book in 2005, Frankenstein's works could have been used to create an army of docile soldiers or workers, echoing contemporary preoccupations about the possible uses of cybernetics and bioengineering. Steampunk does not dissociate scientific findings from their practical applications, and makes a point of showing their consequences. Instead of being destroyed by their work, steampunk doctors change the whole society they work in. Before asking whether such a change is positive or negative, steampunk authors postulate an essential possibility: whether they are positive or negative, remarkable changes may be successful, and transform society instead of destroying their initiator.

One characteristic of the steampunk doctor is that they often appear as a figure of power. They either enjoy a legendary reputation, or they have considerable resources and influence at their disposal; in any case, one of the most important differences between $19^{\text {th }}$ century mad scientists and steampunk doctors is that the latter rarely have to work in obscurity. Helen Magnus, the leader of the Sanctuary network, appears to have almost unlimited financial resources and clout, although it is never clearly explained how she came by such power, nor how she managed to conduct her activities in an extravagant mansion for over a century and never be questioned. Her possible struggles to financially maintain her efforts are not the focus of the series; her power is instead taken for granted, a defining trait of her character rather than something earned and fought for. In a slightly different vein, Dr. Minnericht in Cherie Priest's Boneshaker (2009) becomes the leader of the underworld by using his medical skills as a lever in order to reinforce his influence. While not all steampunk doctors are figures of power (neither Grimnebulin nor Jack Seward are particularly powerful, although they enjoy a certain reputation), clout and resources are very often part of the persona. Interestingly, this is not simply a reflection of the fact that in popular imagery, doctors are supposed to have a special social status. A person who can transform the fabric of society is logically associated with power. It is usually a markedly unofficial power, however, thus further accentuating the questions surrounding the legitimacy of the doctor's actions. But it reflects an important point: in steampunk, doctors do not have power solely over individual bodies. Their transformative influence can extend over a whole society. As they gain power to modify a great number of individuals, steampunk doctors open the possibility of re-shaping entire societies, by privileging some individual over others, or by transforming entire groups to suit a definite agenda.

The characters we have just described have much in common with the classical figure of the mad scientist, as various media from the $19^{\text {th }}$ century onward have popularised it. First, they are largely solitary, operating alone or with a small group of selected people (the Fixer is the associate of the mysterious Dr. Fabian, the private physician of the Queen; Darwin, Galton, Brunel and Nightingale systematically operate together...). Secondly, while the Victorian era in steampunk is portrayed as a period of technological advances, the broader intellectual context where those advances are made is hardly ever mentioned. Most often, the work of one person is presented as a groundbreaking advance, both on theoretical and on practical levels, with the power to change both 
the scientific and the technological framework of the times. The actual history of medicine hardly gives examples of such extraordinary individuals, capable of entirely transforming science by themselves. Thus, the figure of the mad scientist, and by extension, the steampunk scientist and the steampunk doctor, are more symbolic than realistic: they represent the impact of dramatic scientific advances made in little time. Narratives from the $19^{\text {th }}$ century often focused on the destructive impact of scientific progress unrestrained by ethical considerations: by showing the demise of the mad scientist, they were showing progress crumbling on itself, becoming self-destructive through its sheer magnitude. Steampunk, however, was developed in a different context, possibly explaining the evolution of that trope. Instead of being destroyed, steampunk doctors manage to realise their ambitions, at least partially. They are allowed to get past the stage of theories and prototypes and to introduce their discoveries in society, for better or for worse. By definition, the steampunk doctor is a successful mad scientist, in a society that has to make room for mad science-and sometimes accept to be ruled by it, as Europa is taken over by mad scientists in Phil and Kaja Foglio’s Girl Genius (2001-present).

When imagining the consequences of modifying and improving human bodies, one first has to consider the fact that in most societies, a limited number of people have a large amount of power and influence. Acting on those people therefore means having a larger impact on society as a whole: for instance, what if an influential leader could be made immortal? In Mann's aforementioned novels, by extending Queen Victoria's life indefinitely, her personal physician extends the entire Victorian age. Although this speculation might be somewhat simplistic (Victoria was a powerful symbol, but she can hardy be considered to have been single-handedly responsible for the society of her times), it still asks whether a whole society could be transformed by acting upon a limited number of people. Obviously, the answers can vary widely across the steampunk genre, but the question is recurrent: DiFilippo's answer is quite antithetical to Mann's, as he shows the queen being replaced by a human-newt hybrid with no one the wiser. While this particular story is more facetious than philosophical, it exemplifies our earlier claim: steampunk bases its ethical reflexions on technologies on realisations, not on potentialities. The issue at stake here is not that a human-newt might replace the ruler of a country, but that it hasand that, indeed, no major disruption ensues.

What can be done to one individual can be used to transform society to its core. Applied on large numbers of individuals, the modifications performed by the steampunk doctor can result in new social classes, defined by the way their bodies are altered. In that regard, the steampunk doctor does not simply heal or improve individuals. They are often aware of that fact: many steampunk doctors act with the purpose of eventually transforming their society, either on a microscopic or on a macroscopic level. In Mechanique, Boss creates her own microcosm, but while she is very successful at engineering a community inside her circus troupe, her efforts do not influence what happens in the wider world. In The Iron Duke, the Blacksmith reaches much farther: by taking workers and grafting mechanical instruments on their limbs, he effectively creates a society of castes, where people literally become their job. The Eugenicists from The Strange Affair of Spring-Heeled Jack have even larger ambitions, as they plan to genetically modify entire swathes of humankind, in order to turn not only them into living tools for their trade, but their offspring as well. Acting on individuals appears to be a means to a larger end: transforming society as a whole.

Of course, not all of those doctors are successful. The Eugenicists are ultimately foiled, and so is Moriarty from The League of Extraordinary Gentlemen in his plans to make an army of supermen. But even the most questionable projects are always partially realised, if only as prototypes. For instance, what allowed Moriarty to form his plans in the first place was the existence of extraordinary abilities in some individuals, which he wished to replicate. Steampunk doctors are not doomed by their very efforts, but contribute to shaping a new society, either by fully realising their projects or by setting changes in motion. Steampunk celebrates hubris instead of insisting on its dangers. The fascination the doctor exerts is as strong as the repulsion some of the most worrisome schemes may inspire. Furthermore, the notion of a "greater good" exists in close parallel to the trope of the evil scientist looking for personal power. The idea that the ultimate betterment of society justifies any transgression on the part of the doctor may have been largely contested in official discourses, but it has never ceased to be a source of ethical uneasiness-especially since unethical practices in medicine and medical research have endured long past the $19^{\text {th }}$ century (Francis, 2001)—a fact that is often reflected in steampunk narratives. But the more specific question asked by steampunk does not really concern the dialectics between a hypothetical greater good, individual human rights and destructive personal ambition, as such questions should be asked before progress takes place. Steampunk considers what becomes of those ethical problems once scientific advances have already made their way into society. 
The fact that technical progress is unavoidable renders ethical questions moot to a certain degree, but does not erase the necessity of such questionings. The potential negative consequences have to be recognised, but extremely advanced medicine is never portrayed completely negatively. Much of steampunk, in fact, represents worlds in which ethics are not a powerful driving force. It has been noted that the ethos behind steampunk owes much to counter-hegemonic philosophies or anarchism (Bowser \& Croxall, 2010; Ferguson, 2012). As a result, the idea of a fixed definition of ethics organising the fictional world runs counter to a large part of the movement, and even when the heroes are ethical characters themselves, the organisational forces in the fictional universe, and motivating forces behind the plot, are usually amoral, and may allow events with dreadful ethical consequences to take place.

\section{Conclusion}

The figure of the steampunk doctor is the focal point of many questions. It calls for a new definition of the act of healing, in a society where bodies cannot only be restored to a healthy state, but improved far beyond it. It questions the meaning of "improvement" in the context of medicine, and whether it is ethical for medical practitioners to bring human bodies beyond their normal state, to the point that normality itself has to be re-defined. Finally, it brings to the forefront some ethical questionings that are very relevant to the present times, in spite of the deceptively retrospective aesthetics.

Indeed, showcasing incredibly advanced science in a context reminiscent of the $19^{\text {th }}$ century can be a way to look back on a time when progress was either perceived as threatening, but in some ways avoidable, or as a source of hope, while voicing questions and concerns about the progress that did, and will, happen. The very modern issues of biological manipulations and human enhancement, as well as the ethical limits of medicine, are echoed by the seemingly archaic views of eugenicists and social Darwinists, and in the context of the Victorian era, where bioethics had yet to be invented and much could be done in the name of science, they are allowed to reach frightening proportions. In such a context, where progress is already happening, ethical issues become particularly complex, as they apply not to a theoretical phenomenon, but to an unavoidable reality. The steampunk doctor holds a particular position: they are at the same time driving medical progress and driven by it, servants of their science and masters of their art with nearly unlimited power over individuals and societies.

Thus, ethical ambiguity exists on a number of levels: in the persona of the doctor, because of the nature of their actions, but also because of the observed consequences of those actions: how they transform the steampunk doctor into something more than a medical practitioner, their impact on the human body and their impact on society as a whole. In conclusion, this grey area describes the steampunk doctor: they are a missing link between the inanimate and the living, biology and mechanics, heralding the potential reconfiguration of society around the possibility of unbounded artificial life.

\section{References}

Arakawa, H. (2001-2010). Full Metal Alchemist. San Francisco: Viz Media.

Bostrom, N., \& Sandberg, A. (2008). The Wisdom of Nature: An Evolutionary Heuristic for Human Enhancement. In N. Bostrom (Ed.), Human Enhancement (pp. 375-416). Oxford: Oxford University Press.

Bowser, R., \& Croxall, B. (2010). Introduction: Industrial Evolution. Journal of Neo-Victorian Studies, 3, 1-45.

Brook, M. (2010). The Iron Duke. New York: Berkley Books.

Caro, M., \& Jeunet, J. P. (dir). (1995). The City of Lost Children. Adrien, G., Caro, M. \& Jeunet, J. P. (writ). UGC.

Colson, R., \& Ruaud, A. F. (2006). Science-Fiction: une littérature du réel. Paris: Klincksieck.

DiFilippo, P. (1997). The Steampunk Trilogy. Philadelphia: Running Press.

Ferguson, C. (2011). Surface Tensions: Steampunk, Subculture and the Ideology of Style. Journal of Neo-Victorian Studies, 4, 66-90.

Foglio, P., \& Foglio, K. (2001-present). Girl Genius. http://www.girlgeniusonline.com

Forlini, S. (2010). Technology and Morality: The Stuff of Steampunk. Journal of Neo-Victorian Studies, 3, 72-98.

Foucault, M. (1973). The Birth of the Clinic: An Archaeology of Medical Perception. Sheridan, A. (trad). London: Routledge.

Francis, C. K. (2001). Medical Ethos and Social Responsibility in Clinical Medicine. Journal of Urban Health: Bulletin of the New York Academy of Medicine, 78, 29-45. http://dx.doi.org/10.1093/jurban/78.1.29 
Freidson, E. (1970). Professional Dominance: The Social Structure of Medical Care. Piscataway: Transaction Publishers.

Guitton, M. J. (2013). Morphological Conservation in Human-Animal Hybrids in Science Fiction and Fantasy Settings: Is Our Imagination as Free as We Think It Is? Advances in Anthropology, 3, 157-163. http://dx.doi.org/10.4236/aa.2013.33021

Heilmann, A., \& Llewellyn, M. (2010). Neo-Victorianism: The Victorians in the Twenty-First Century. Basingstoke: Palgrave Macmillan. http://dx.doi.org/10.1057/9780230281691

Hodder, M. (2010). The Strange Affair of Spring-Heeled Jack. London: Snowbooks.

Hogle, L. F. (2002). Introduction: Jurisdictions of Authority and Expertise in Science and Medicine. Medical Anthropology: Cross-Cultural Studies in Health and Illness, 21, 231-246. http://dx.doi.org/10.1080/01459740214076

James, E. (1994). Science Fiction in the 20th Century. Oxford: Oxford University Press.

Jeter, K. W. (1987). Infernal Devices. New York: St Martin's Press.

Kamm, F. M. (2005). Is There a Problem with Enhancement? The American Journal of Bioethics, 5, 5-14. http://dx.doi.org/10.1080/15265160590945101

Mann, G. (2008). The Affinity Bridge. London: Snowbooks.

Mann, G. (2011). The Immorality Engine. London: Snowbooks.

Miéville, C. (2003). Perdido Street Station. New York: Del Rey Books.

Nevins, J. (2011). Prescriptivists versus Descriptivists: Defining Steampunk. Science Fiction Studies, 38, 513-518.

Newman, K. (1992). Anno Dracula. New York: Simon \& Schuster.

Norrington, S. (Dir.) (2003). The League of Extraordinary Gentlemen. J. D. Robinson (Writer), Los Angeles, CA: 20th Century Fox.

Onion, R. (2008). Reclaiming the Machine: An Introductory Look at Steampunk in Everyday Practice. Journal of Neo-Victorian Studies, 1, 138-163.

Perschon, M. (2010). Steam Wars. Journal of Neo-Victorian Studies, 3, 127-166.

Priest, C. (2009). Boneshaker. New York: Tor Books.

Robert, J. S., \& Baylis, F. (2003). Crossing Species Boundaries. The American Journal of Bioethics, 3, 1-13. http://dx.doi.org/10.1162/15265160360706417

Saint-Gelais, R. (2011). Fictions Transfuges. Paris: Seuil.

Schwartz, P. H. (2005). Defending the Distinction between Treatment and Enhancement. The American Journal of Bioethics, 5, 17-19. http://dx.doi.org/10.1080/15265160591002755

Sedia, E. (2008). The Alchemy of Stone. Gaithersburg, MD: Prime Books.

Shelley, M. (1818). Frankenstein or the Modern Prometheus. London: Lackington, Hughes, Harding, Mavor and Jones.

Stephenson, N. (1995). The Diamond Age. New York: Bantam Spectra.

Stevenson, R. L. (1886). The Strange Case of Dr. Jekyll and Mr. Hyde. London: Longman and Green, Co.

Valentine, G. (2011). Mechanique. Gaithersburg, MD: Prime Books.

Wells, H. G. (1896). The Island of Doctor Moreau. London: Heinemann, Stone and Kimball.

Westerfeld, S. (2009). Leviathan. New York: Simon Pulse.

Wolf, T. (2005). Barton-Wright's Misadventures in Electrotherapy. In T. Wolf (Ed.), The Bartitsu Compendium, Volume 1: History and the Canonical Syllabus (pp. 63-67). Raleigh, NC: Lulu Press.

Wood, M. (Dir.) (2008-2011). Sanctuary. New York: Syfy. 